\title{
Why People Get Divorced
}

\author{
By PÄIVI ELOVAINIO \\ University of Helsinki \\ Department of Social Policy
}

The rise in divorce in Finland began around the turn of the century at the same time as the breakthrough of industrialization. Excluding the rapid rise in divorce in the years after World War II the growth in the rate of divorce has continued parallel to the industrialization process in society (Anttila, 1976). It can be noted, on the basis of information available of countries where industrialization and urbanization are greater than in Finland (Demographic Yearbook 1973,373 ) that the growth in divorce in Finland has corresponded to the universal trend in development. It is worth noting, however, that although the association of the development of divorce with industrialization, urbanization and other such structural changes in society is most readily observed, at the same time distinct ideological and attitudinal changes have also taken place, which are unmistakably connected to the increase in divorce. For example, Paavo Seppänen (1965 and 1974) has, in examining the transition in Finnish society on the basis of empirical material, shown that this transition included two basic and distinct processes of change, one of which reflects the process of change in the organizational structure and the other the ideological transition. Definite correlations were found between both central variables describing these two processes of change and variables describing family functions and also variables measuring divorce. The change which has taken place has, in addition to narrowing the significance of the family as a social institution provided for the satisfaction of the individual's needs.

The aim of this study, ${ }^{1}$ which was based on empirical data, was to examine the reasons for divorce. The hypotheses in this study were based on Clayton Alderfer's theory (1969) on the significance of human needs, the possibilities for need satisfaction and the compensativeness of needs and the meaning of the family in this process. Special attention has been paid to how changes in the importance of the family as an institution caring for the satisfaction of neers has caused marital discord and led to divorce.

This study is based on questionnaire data gathered from 210 residents of Helsinki, who received a decree of divorce in 1975. The small size of the sample and the fact that it includes only residents of Helsinki and people divorced during one certain year limits the degree to which these results can be general-

1 This article is a synopsis of a study made by the author: Päivi Elovainio, Avioerot Suomessa, The Population Research Institute series D, No. 4, 1976. 
ized. The results of this study can only be considered orientative. A plan is underway to use these as a basis for designing a more thorough study, which would be broader in scope than this pilot study both in geographical area and in time and which would also include comparison data on married people.

\section{Satisfaction of needs and divorce}

In examining the reasons for divorce it proved important to examine what kind of needs are generally essential to human well-being and satisfaction and what is the role of the family/marriage in fulfilling possibilities for need satisfaction. The study has attempted to answer the following question: is the increase in the frequency of divorce connected to changes in the possibilities for need satisfaction in family and conflicts arising from these changes. However, the research data was gathered from only one time period, so that it was not possible to study any actual change. Therefore assumptions on the effect of past development on the current situation have been made using only the theoretical framework used in the study. On the whole one can say that the changes which have taken place have brought about a reduction in the significance of the family as an institution providing possibilities for the satisfaction of an individual's needs, thus decreasing pressure to keep the family together and increasing the possibility to break away from family ties.

In the study needs were divided into three types of basic needs according to Alderfer's theory: existence needs, relatedness needs and growth needs. Existence needs include all physiological, material and physical security needs. Relatedness needs include social contacts and the need to be loved and accepted. Growth needs consist of all demands for self-realization. According to Alderfer's theory, needs - the satisfaction of needs - are generally hierarchical so that the satisfaction of existence needs must be safeguarded before on can begin to satisfy relatedness needs and relatedness needs must be safeguarded before growth needs can be satisfied. This hierarchism is not complete, however, in that Alderfer's theory includes the assumption that some needs can be compensated by overemphasizing other needs. Alderfer's theory includes hypotheses, based on empirical research, on how this compensation generally takes place. In the study at hand these hypotheses were used as a basis for drawing up a set of assumptions on how the change in the structure and functions of the family and the change in the family, marriage and sexual attitudes have caused conflicts in the possibilities for need satisfaction.

The importance of the family as an institution providing the satisfaction of needs has changed, compared to the earlier situation where there was little divorce, in that its function as a provider of subsistence and security has decreased in importance. Similary, in addition to the fact that opportunities for the satisfaction of growth needs have increased in general in society, they have been transformed in that their realization within the family and the home is 
rarer than before (cf. Haavio-Mannila, 1968, 35-37, Komiteamietintö 1972, $28-31$ ). On the part of the need satisfaction taking place within the family, the decrease in the realization of subsistence and security needs and growth needs has meant greater emphasis on relatedness needs.

\section{The ideal of romantic love and marital happiness}

On the basis of this study the increasing emphasis on "lover» relatedness needs as a prerequisite to marriage has increased the prevalence of an unrealistic attitude toward marriage and the problems in entailed. Here it is significant that while $80 \%$ stated that love was the most important grounds for their having married, $39 \%$ of the women and $17 \%$ of the men said that marital conflicts already began during the first year of marriage and $28 \%$ of the women and $19 \%$ of the men said they began during the second year. People were especially disappointed in the lack of tenderness and sexual relations (Table 1). The expectations of both men and women concerning emotional ties seem to have been greater than they were able to achieve in reality. The degree to which dissatisfaction with the relationship between the spouses was primary or a result of other factors, e.g. financial difficulties, is difficult to determine on the basis of this study.

Conflicts related to the emphasis on relatedness needs - and the preservation of the ideal of romantic love - are probably caused not only by the changes in the functions and structure of the family but also by the fact that attitudes toward the family/marriage and sexual behavior have most likely been slower to change than the structure of the family. The attitudes toward traditional social institutions have generally changes slower than structural renewal, which has caused conflicts in a time of rapid social transition. The assumption can be made that the current situation, the conflict situations it brings to marriages and the increase in divorce are to some degree a passing phase, because attitudinal change has not yet had time to adapt to structural change. However, in the future fixed couples will probably last no longer than now, but divorce in juridical terms will decrease because the forms marriage takes will change.

\section{The reasons for divorce in different social groups}

In examining marital conflicts caused by opportunities for need satisfaction it could be shown that they differed according to social group. In the lowest social groups there was an emphasis on the conflict between existence needs and relatedness needs, while in the highest group conflict situations arose most prevalently between the satisfaction of relatedness needs and growth needs.

It is significant, however, that a closer examination of what kind of factors concerning existence needs - subsistence, standard of living and wellbeing or changes therein - cause the most conflicts, showed that this was changes in 
$\mathrm{Table}$ 1. Factors which did not meet expectations of marriage, according to sex: (1) came least up to expectations, (2) came second least up to expectations

\section{Women}

(1)

Received less tenderness than

expected

Sexual relations did not

meet expectations

Marriage limited independence

more than expected

Financial situation worse than

expected

Own use of money more limited

than expected

Housework and childcare more strenuous than expected

Other reason

\section{Men}

(1)

15

0

13

$100 \%$

(89)

the use of money (c. $40 \%$ of the respondents). Changes that had occurred in the use of money were mainly increases in the amount of money the husband had for his own use. Here the basic reason was not to be found in changes in the financial situation, but instead most likely in changes which had occurred in the relationship between husband and wife and which had led to the husband directing more of his activities and spending more of his money outside the home. It was surprising to find in examining the significance of existence needs in marital conflicts that income or changes in income were not experienced as having a direct effect on the happiness of the marriage. On the other hand, the crowdedness of the dwelling and the opportunities for finding childcare were, among the factors measuring existence needs and security needs, seen as next in importance to the spending of money as causes of marital conflict. Most likely the level of income is considered a "given" factor and, also, very rarely is there a definite decrease in the level of income during marriage, which would mean that its effects are not seen as essential factors in marital conflicts. The fact that the dwelling becomes crowded and childcare must be arranged and paid for are questions that come up in almost every marriage when the family grows, causing an increasing number of conflicts.

The increase in the share of expenses caused by the husband's own expenditures has been associated with an increase in the use of alcohol. It is significant that while in the upper class the most central cause of marital discord was associated with the relationship between spouses and especially with faithfulness in marriage, in the middle and working classes alcohol played a central role in marital disharmony. Alcohol caused much difference of opinion in $48 \%$ of those from the middle class and $43 \%$ of those from the working class, but in 
only $12 \%$ of those classified as belonging to the upper class. However, no distinct differences in the use of alcohol could be seen in the different social groups. Alcohol expenditures probably meant a noticeably larger share of the amount of money people in the middle and working class had to use than it did in the upper class. Differences between social groups in the significance the use of alcohol has as a cause of marital discord are probably primarily a result of the share alcohol expenses take up in the family budget and/or perhaps also a result of a different attitude toward alcohol.

In the upper class the conflict between growth needs and relatedness needs are given greater emphasis than the others. Men, especially, emphasized the disadvantages caused by the wife being employed. This finding was in conflict with the finding that the attitude the upper class generally held toward the family, marriage and sexual behavior was the most liberal and reform-minded of all. In this study the conflict between behavior and attitudes was seen as mainly caused by the fact that in the upper class the satisfaction of growth needs was characteristic of both spouses and that the question was not so much a conflict of values rather a conflict of interests, meaning which spouse will be given the opportunity to act and the opportunity to satisfy growth needs outside the home.

\section{The attitudes of men and women toward marriage}

It is worthy of remark, however, that the differences between social groups in evaluating the causes and consequences of marital conflicts were not as great as the differences apparent between the sexes. For example, women felt there had been more conflicts in their marriages than did men (Table 2).

$\mathrm{Table} 2$. The percentage of people saying that the following factors caused a great difference of opinion in their marriage, grouped according to sex

Own or spouse's use of money

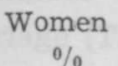

Men

Children's use of money

Children's upbringing

Care of the home

Sharing housework

Sexual relations

Unfaithfulness

Visiting and keeping company with

relatives and friends

Political opinions and opinions on religion

Different freetime hobbies and interests 
The large differences of opinion between the sexes as to which factors cause much discord in marriage are surprising, in that the study sample was composed of married couples. The result can probably be explained by the fact that women had greater expectations of marriage and that women are more dependent on their family making women less able to tolerate marital conflicts. Women also suggest and apply for divorce noticeably more often than do men (Table 3), and for men the application for divorce comes as a much greater sur-

$\mathrm{Table} 3$. The initiator of the divorce process

$\begin{array}{llc} & \text { City } & \text { Rural area } \\ \text { Woman } & 58.3 & 64.7 \\ \text { Men } & 21.8 & 18.6 \\ \text { Joint application } & 19.91 & 16.41 \\ & & 1 \text { (also includes cases } \\ & & \text { where both parties are } \\ \text { (Helin } 1975,162) & & \text { the plaintiff) }\end{array}$

prise than it does to women (Table 4). Men again seem to have had greater opportunities for need satisfaction outside the home.

$\mathrm{T}$ a ble 4 . Was the suggestion of separation/divorce a surprise to one spouse or the other

To whom it was

a surprise

Women Men

To neither

To me

To my spouse

Unknown

\begin{tabular}{cc}
59 & 72 \\
10 & 24 \\
28 & 3 \\
3 & 1 \\
\cline { 2 - 2 } $100 \%$ & $100 \%$ \\
$(105)$ & $(100)$
\end{tabular}

The conflict between the sexes has probably had been more emphasized in the last few decades, because the education of women and their employment outside the home have become more common. Conflict situations in the family seem primarily caused by the fact that attitudinal change has been slower than the changes that have occurred in the structure and function of the family. Since traditional expectations concerning male and female roles have been slower to change than the changes in the position of women, this has caused inequality between men and women, for example because the division of labor 
within the family as well as the opportunities for activity outside the home have not changed so that they would correspond to the changes which have taken place in the position of women and the relations between spouses. Besides the division of labor and the opportunities for activities outside the home, inequality between men and women is pronounced in economic factors. According to the study, for example, regardless of social group the differences in income between men and women were large as were the differences among men and women in how much money they had to spend on their own needs (Table 5).

$\mathrm{T}$ a ble 5. Spending money on own personal needs during marriage, grouped according to sex

The spouses used money:

About an equal amount

Spouse uses a great deal more

Spouse uses somewhat more

I use a great deal more

I use somewhat more

\begin{tabular}{cc} 
Women & Men \\
33 & 45 \\
44 & 11 \\
16 & 13 \\
0 & 11 \\
7 & 20 \\
\hline $100 \%$ & $100 \%$ \\
$(104)$ & $(98)$
\end{tabular}

\section{Attitudes toward sexual behavior and divorce}

The study also attempted to discover whether divoried people had somewhat different attitudes toward the family, marriage and sexuality and how these attitudes affect the rate of divorce. No clear-cut differences were found, however, between the attitudes of married people and of divorced people (Table 6). On the other hand, for example, the number of extramarital relations during marriage was much higher among the divorced men and women than it was among married people, for whom the number of extramarital relations was associated with the happiness of the marriage (Table 7).

\section{The model for marriage provide by the childhood home}

The hypothesis presented in many studies on the significance for the happiness of one's own marriage held by the happiness of one's childhood and the harmony of one's childhood home and the sexual roles learned during childhood finds support in this study as concerns the happiness of one's parents' marriage (Table 8). According to this study the frequency of divorce among the parents of the divorced was also greater than was usual in the corresponding age class of the whole population. 
$\mathrm{T}$ able 6 . Attitude toward sexual behavior

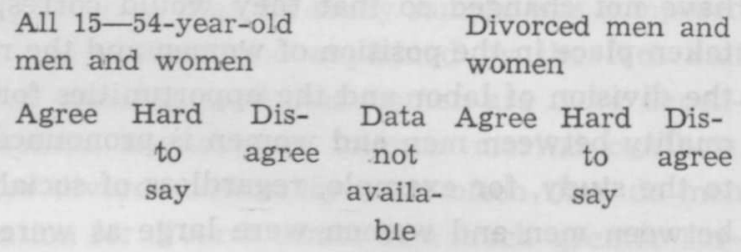

Women have the right to take the initiative when they want to have sexual relations with a man

$\begin{array}{rrrrrrrr}\text { M } & 92 & 3 & 4 & 1 & 89 & 1 & 9 \\ \text { F } & 75 & 11 & 13 & 1 & 62 & 8 & 20\end{array}$

Men are by nature polygamous, while women are monogamous

Sexual intercourse without love is wrong

$\begin{array}{rrrrrrrr}\text { M } & 89 & 5 & 5 & 1 & 74 & 8 & 18 \\ \text { F } & 81 & 6 & 12 & 1 & 83 & 9 & 8\end{array}$

$\begin{array}{lllllll}\text { M } & 41 & 20 & 39 & 38 & 12 & 50 \\ \text { F } & 64 & 15 & 20 & 45 & 17 & 38\end{array}$

It is good that there are reform-minded groups in society who defend more liberal moral trends

$\begin{array}{llllllll}\text { M } & 46 & 26 & 26 & 2 & 46 & 14 & 38 \\ \text { F } & 60 & 19 & 20 & 1 & 32 & 20 & 36\end{array}$

(Sievers, Koskelainen, Leppo 1974) (This study)

$\mathrm{Table} 7$. Correspondence between happiness of marriage and extramarital relations, for men and women

Happiness of the marriage

Married people

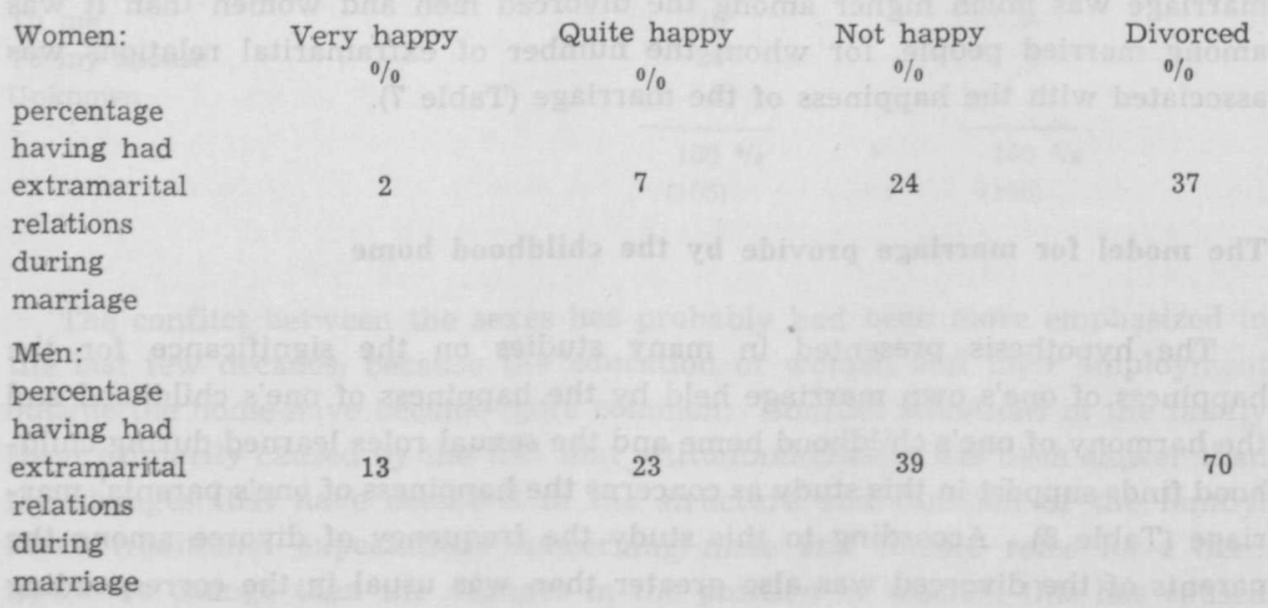

(Sievers, Koskelainen, Leppo 1974)

(This study) 
Table 8. Are one's own or one's spouse's parents divorced

Women

Men

Own parents

divorced

$20 \%$

$24 \%$

Spouse's parents

divorced
$20 \%$

(104)
$28 \%$

Comparison with figures available on the mean population are difficult in that the frequency of divorce, which is calculated from the mean population, always describes a cross-sectional situation and is weighted by the distribution of the length of marriage in years in this group. However, Kirsti Anttila (1976) calculated divorce by age cohorts and length of marriage and discovered that in the age groups over 55 years of age, where the frequency of divorce is no longer increasing and who most likely also best represent the age group of divorced parents, the percentage of divorce among women was $10-11 \%$. On the basis of this result it can be assumed that the example set by the parents has a share in determining the kind of conceptions and behavior models one sets up for the need satisfaction in family.

In a further study an attempt will be made not only to broaden the base of the study geographically and temporally, but also to increase comparisons with married people, and to make a closer examination of the empirical results in the light of need satisfaction theories. It is also necessary to gather historical material, in order to see how the duties of the family/marriage and its significance as a social institution providing need satisfaction have changed. The changes which have taken place in the family should be seen as a part of the changes which have occurred in the economic, social and political systems of society, and the increase in divorce should be seen as a result of this change.

\section{References}

Alderfer, Clayton, An empirical test of a new theory of human needs. Organization of Behavioral and Human Performance 1969, 4,

Anttila, Kirsti, Avioerat Suomessa, manuscript for a pro gradu-study at the Sociology Institute of the University of Helsinki.

Haavio-Mannila, Elina, Suomalainen nainen ja mies, Helsinki 1968.

Helin, Markku, Suomalainen avioeroprosessi, Helsinki 1974.

Komiteamietintö A: 211972.

Sievers, Kai, Koskelainen, Osmo ja Leppo, Kimmo, Suomalaisten sukupuolielämä, Porvoo 1974. 
Seppänen, Paavo, Muuttuva yhteiskunta, Sosiologia 2, 1965, 73-89.

Seppänen, Paavo, Dimensions and Phases of Change in Finnish Society (mimeograph 1975).

Statistics:

Demographic Yearbook 1973.

Helsingin kaupungin tilastollinen vuosikirja 1974.

Suomen tilastollinen vuosikirja 1974.

Suomen virallinen tilasto.

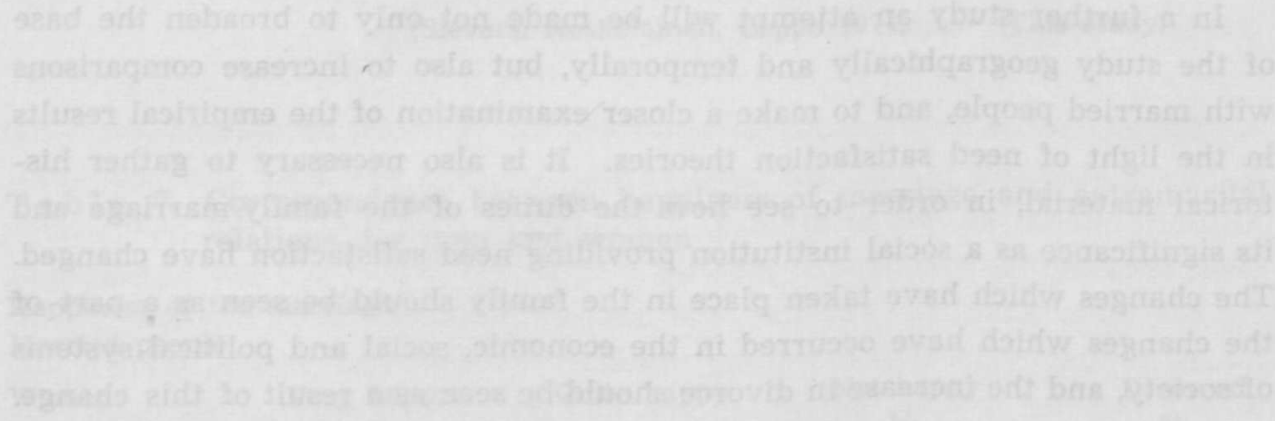

